\title{
A Practical and Simple Method of Recycling Catalyst in Asymmetric Aminohydroxylation of Olefins
}

\author{
Xiao Li Sun, Ying Jin, Wei He, Peng Jıan Nan, and Sheng Yong Zhang*

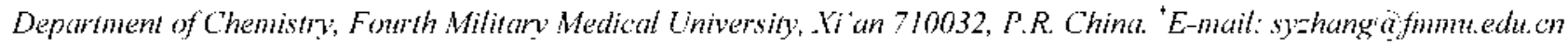 \\ Recived November 25,2005
}

Key Words : Monomeric cinchona alkaloid ligand, $\Lambda$ symmetric aminohydroxylation, Recycle, Chiral $\beta$-aminoalcohol

The Os-catalyzed asymmetric aninohydroxylation $(\Lambda \Lambda)$ of olefins provides a straightforward method for the enantioselective synthesis of a wide variety of protected vicinal aminoalcohols. ${ }^{1-4}$ The resulting chiral faminoalcohols group is the most abundant structural element in many biologically active molecules as well as the starting point in the design of many chiral ligands. ${ }^{5-7} \Lambda$ lthough $\Lambda \wedge$ reaction servers as a powerful method for the synthesis of a variety of products, its application has still been limited because of the high cost of osmium and chiral ligand. In order to explore the possibility of the repetitive use of ligand andior osmium, several attempts to immobilize this catalytic system have been made. Nandanan group prepared highly crosslinked copolymers between ethylene glycol dimethacrylate 90 mol\%) and a bis(quininyl)pyridazine derivative (10 $\mathrm{mol} \%$ ). This insoluble ligand was then used in AA reaction of various olefins in $52-65 \%$ yields and $34-54 \%$ ees. Up to now, many insoluble polymer-supported ligands have been successfully reused in AA reaction, ${ }^{8-11}$ Yang lirst reported an immobilized soluble PГC-bound bis-cinchona alkaloid ligand which could be recovered and reused in homogeneous AA reactions. Fxcellent yields and ees were obtained in homogeneous system. ${ }^{12}$ In most reported recycling methods, osmium component was hardly recovered and sometimes synthesis route of the polymer-supported ligands were complicated. Here we report a recyclable monomeric ligand
1 and its application in homogeneous AA reaction. In addition, poly(ethylene glycol) (PEC MW 400) linked with the special encapsulating effect on osmium was successfully applied in AD reaction, ${ }^{13}$ Enlightened by this, we applied PEG in AA reaction for the recovery of osmium and achieved an amazing result that about $50 \%$ amount of osmium component could be efficiently recycled through very simple method.

\section{Results and Discussion}

According to the similar synthesis method, ${ }^{1+}$ ligand 1 was prepared by simple three-step reaction (Scheme 1), 3,6Dichoropyridazine reacted with quinine in presence of $\mathrm{NaH}$ in DMF to give compound 2 ( $80 \%$ yield), which was heated with 2-mercaptoethanol in the presence of 2,2'-azobisisobutyronitrile (AlBN) in $\mathrm{CHCl}_{3}$ to give the sulfide $3(66 \%$ yield). Compound 3 was then oxidized to the desired sulfone 1 using a mixture of $\mathrm{OsO}_{4} / \mathrm{N}$-methylmorpholine $\mathrm{N}$-oxide (NMO) in $\mathrm{THF} / \mathrm{t}-\mathrm{BuOH}(3: 1)$ at room temperature $(79 \%$ vield).

l.igand I was applied in the homogeneous AA reactions under conventional Sharpless conditions using benzyloxycarbonyl carbamate as the oxidant-nitrogen source. The results were summarized in Table 1.

As can be seen from Table 1, all of the six selected olefins<smiles>CCN1C2CCC1CC(C(O)c1ccnc3ccc(O)cc13)C2</smiles>

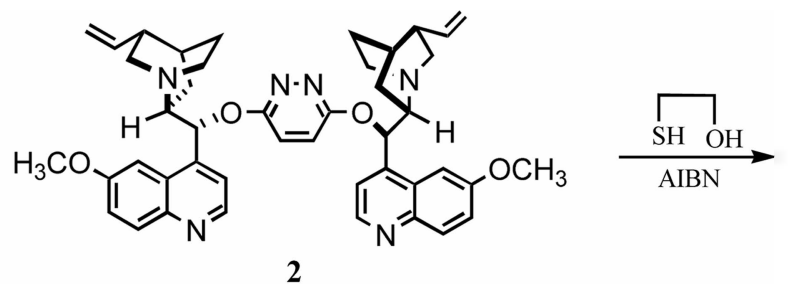

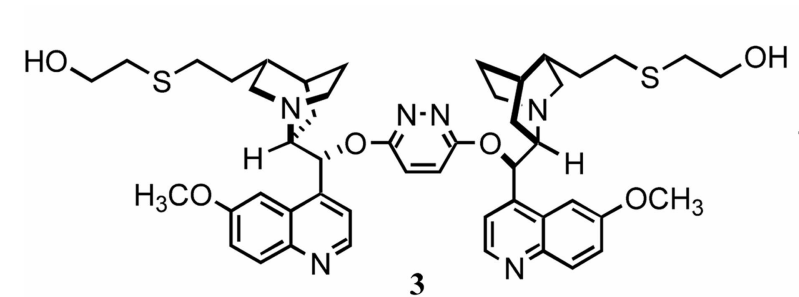

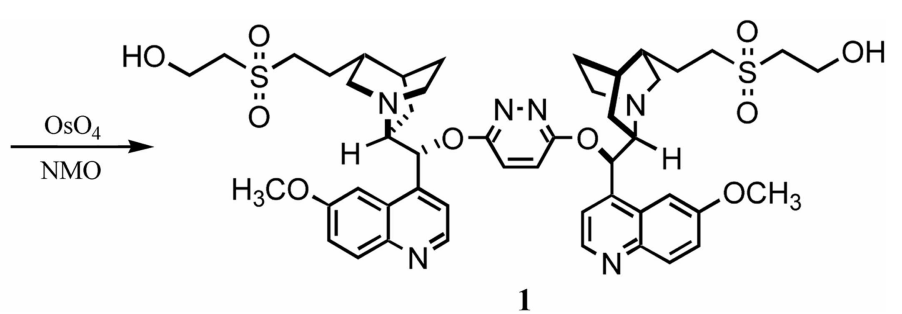

$\left[\mathrm{QN}\left(\mathrm{SO}_{2} \mathrm{CH}_{2} \mathrm{CH}_{2} \mathrm{OH}\right)_{2}\right]_{2} \mathrm{PYDZ}$

Scheme 1. The synthesis route of ligand 1. 
Table 1. The homogeneous asymmetric AA reaction using ligand $1^{a}$

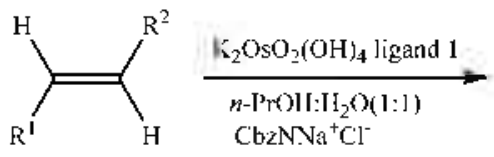

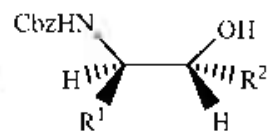

A

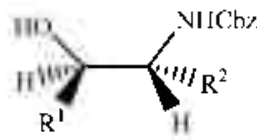

B.

\begin{tabular}{|c|c|c|c|c|c|}
\hline Entry & Olctins & Product (A) & Regiosclectivity $(A: B)^{h}$ & Yicld $(A+B)(\%)^{\prime}$ & oce $(\mathrm{A})^{d}$ \\
\hline 1 & Styrerle & $2 S$ & $>20: 1$ & 50 & 76 \\
\hline 2 & 2-Naphalene & $2 S$ & $>20: 1$ & 58 & 89 \\
\hline 4 & Fithyl trans-cirmamate & $2 R .3 \mathrm{~S}$ & $3: 1$ & 61 & $>99$ \\
\hline 5 & Iso-Propyl trans-cjonnamale & $2 R .3 S$ & $2: 1$ & 70 & 98 \\
\hline 6 & Cyclohereme & $2 S$ & - & 46 & 12 \\
\hline
\end{tabular}

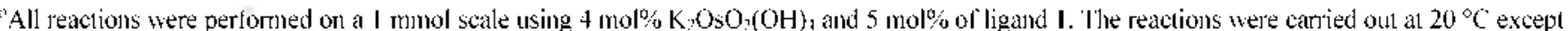
centry $2\left(0^{\circ} \mathrm{C}\right)$. "Dotermincd by ${ }^{1} \mathrm{H}$ NMR spectroscopy. ' Isolated y iclds by column chromatograph. "The ees were determined by chiral HPI $\mathrm{C}$ analy sis.

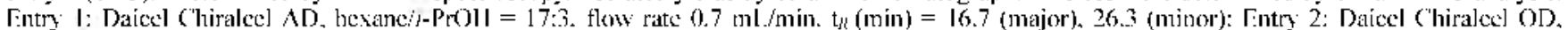

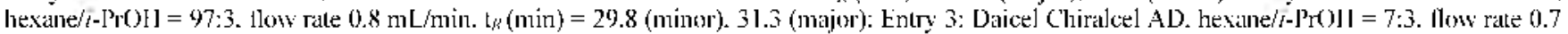

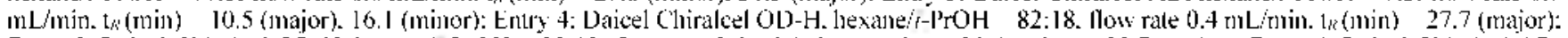

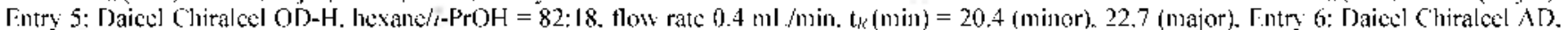
hexanc $t-P r O H=95: 5$. flow rate $0.4 \mathrm{~mL} / \mathrm{min}$. $\mathrm{t}_{R}(\mathrm{~min})=21.7$ (major). 27.5 (minor)

were transformed to $\beta$-aminoalcohols in moderate yields. ligand 1 delivered excellent enantioselectivity for the reaction of trans-cinnamate (Table 1 , entries 4 and 5).

Just like the soluble polymer-supported ligands, the monomeric ligand 1 was completely insoluble in diethyl ether and could be recovered in $80 \%$ according to the reported recycling method. ${ }^{12}$ But the osmium was lost. Therefore, we developed a new approach to immobilize osmium by utilizing the encapsulation ability of PEG. Then we investigated the effect of P'EG and different amount of P'EG on the reactivity and the osmium immobilization. Five AA reactions were performed on a 1 mmol scale with addition of P'EG $0 \mathrm{~mL}, 1.0 \mathrm{~mL}, 1.5 \mathrm{~mL}, 2.0 \mathrm{~mL}$ and $2.5 \mathrm{~mL}$ respectively. When the reaction was finished, the product was extracted with diethyl ether. The ligand 1 still remained in the aqueous phase due to its insolubility in ether while part of osmium leached. We determined the osmium content in the aqueous phase by using inductively coupled plasma atomic emission spectrometry (ICP-AES). The results were shown in lable 2.

The results showed that PEG was essential for the recovery of osmium and $1.5 \mathrm{~mL}$ to $2.0 \mathrm{~mL}$ PEG was the proper amount to encapsulate osmium effectively. More-

Table 2. The effects of the amounts of PEG on the reactivity and immobilization ability.

\begin{tabular}{cccc}
\hline $\begin{array}{c}\text { Amount of PEG } \\
(\mathrm{mL})\end{array}$ & $\begin{array}{c}\text { Yicld }(\Lambda+B)^{b} \\
(\%)\end{array}$ & $\begin{array}{c}\text { \%ec } \\
(\Lambda)^{c}\end{array}$ & $\begin{array}{c}\text { Immobilized Os } \\
(\%)^{\prime \prime}\end{array}$ \\
\hline 0 & 70 & 96 & 9.5 \\
1.0 & 67 & 95 & 43.2 \\
1.5 & 68 & 95 & 49.7 \\
2.0 & 65 & 94 & 50.3 \\
2.5 & 61 & 93 & 50.1 \\
\hline
\end{tabular}

"The reactions were carried out on a I mmol scale with addition of different amount of PF( $i$. Isolated yields by column chromatoreraph. 'Detemined by chiral HPLC' analysis. "Detennined by ICP-AES over, addition of $1.0-2.0 \mathrm{~mL}$ PEG in reaction medium had no obvious effect on the reactivity and enatioselectivity. Accordingly, for recycle experiment. half initial amount of $\mathrm{K}_{2} \mathrm{OsO}_{2}(\mathrm{OH})_{4}$, the initial amount of benzyloxycarbonyl carbainate and $t-\mathrm{BuOCl}$ and proper amount of $\mathrm{NaOH}(\mathrm{pH}=$ II) were added to regenerate the reaction condition. isoPropyl trans-cinnamate was chosen as the substrate to examine the efficiency, with which the ligand and osmium could be recycled. The reaction time of each run was similar (about 7-8 h). The results were shown in Table 3.

The results in Table 3 showed that no significant decrease in activity and enatioselectivity was observed within the first four recycles using the forementioned recycle method.

In summary, we have prepared recoverable ligand $\mathbf{1}$ by simple synthesis with cheap starting materials and applied this monomeric ligand in the homogeneous asymmetric aminohydroxylation. With addition of PEG in reaction medium, the monomeric ligand and half amount of osmium can be easily recycled for at least four times without significant decrease of its activity and enantioselectivity. In addition, the Cbz-protected group is easily cleaved by onestep catalytic hydrogenation reaction in presence of $10 \% \mathrm{pd} /$ $\mathrm{C}$ and $\mathrm{H}_{2}$ to give the free aminoalcohols. ${ }^{15}$ It may improve the possibility of utilizing AA reaction to prepare aminoalcohols in scale.

Table 3. AA reaction of iso-Propyl troths-cinnamate reusing ligand 1 and $\mathrm{OsO}_{4}$ in $\mathrm{PEG}^{\prime \prime}$

\begin{tabular}{ccccccc}
\hline Entry & 1 & 2 & 3 & 4 & 5 & 6 \\
\hline Yicld $(\mathrm{A}-\mathrm{B})(\%)^{6}$ & 70 & 67 & 71 & 69 & 63 & 57 \\
$\% \mathrm{ce}(\mathrm{A})^{\mathrm{r}}$ & 96 & 93 & 96 & 97 & 98 & 94 \\
\hline
\end{tabular}

"Recycle experiments were carricd out on a 1 mmol reaction scale of olefin using $10 \mathrm{mmol} \%$ of ligeand 1 and $2 \mathrm{mmol} \%$ of $\mathrm{K}_{2} \mathrm{OSO}_{2}(\mathrm{OH})_{+}$ (4\% \%mol in the first run). "Isolated yields by column chromitograph. 'Determitzed by chiral HPLC analysis. 


\section{Experimental Section}

NMR spectra were recorded on a Bruker AV-400 spectrometer. High performance liquid chromatography (HPLC) was performed by Agilent 1100 interfaced to a HP 71 series computer workstation with Daicel Chiralcel OD-H. AD chiral column.

Preparation of compound 2. Under nitrogen. a $100 \mathrm{~mL}$ three-necked flask was charged with quinine $(5.2 \mathrm{~g}, 16.0$ munol), 3,6-dichoropyridazine ( $1.20 \mathrm{~g} .8 .0 \mathrm{~nm}$ ol). $\mathrm{NaH}$ ( $1.9 \mathrm{~g}$. $80 \mathrm{mmol})$ and distilled DMF $(30 \mathrm{~mL})$. The mixture was stirred at $60{ }^{\circ} \mathrm{C}$ until TLC indicated that quinine had disappeared. The mixture was cooled to room temperature, filtered and concentrated. The residue was recrystallized with ethyl acetate to give white powder $24.64 \mathrm{~g}$ ( $80 \%$ yield). m.p. 123-125 ${ }^{\circ} \mathrm{C}$ : IR $\left(\mathrm{cm}^{-1}\right): 3418.83,3073.40 .2934 .51,2865.66$. 1621.41. 1509.83. 1434.68. 1261.53, 1027.94,991.66. ${ }^{1} \mathrm{H}$ NMR (400 MHz. $\left.\mathrm{CDCl}_{3}\right): \delta 1.50-1.81(\mathrm{~m} . \mathrm{l0H}), 2.21-2.26$ (m. 2H. CH). 2.57-2.64 (m, 4H, NCHs). 3.02-3.09 (m. $4 \mathrm{H}$. $\mathrm{NCH}_{3}$ ). 3.38-3.40 (m. $\left.2 \mathrm{H}, \mathrm{NCH}\right), 3.92$ (s. $6 \mathrm{H}, \mathrm{CH}_{3} \mathrm{O}$ ), 4.96$5.00\left(\mathrm{~m}, 4 \mathrm{H} \mathrm{H}_{2} \mathrm{C}=\mathrm{C}\right), 5.75-5.84(\mathrm{~m}, 2 \mathrm{H}, \mathrm{HC}=\mathrm{C}) .6 .79(\mathrm{~s}, 2 \mathrm{H})$. 7.00 (s. $2 \mathrm{H}, \mathrm{HCO}), 7.27$ (d, $J=2.0 \mathrm{~Hz}, 2 \mathrm{H} . \mathrm{ArH}$ ). $7.37-7.39$ (m. $4 \mathrm{H}, \mathrm{ArH}$ ), 7.45 (s. $2 \mathrm{H}$. $\mathrm{ArH}$ ), 8.00 (d, $J=9.2 \mathrm{~Hz}, 2 \mathrm{H}$, ArH). $8.68(\mathrm{~d}, J=4.4 \mathrm{~Hz}, 2 \mathrm{H}, \mathrm{ArH}) ;{ }^{13} \mathrm{C}$ NMR $(100 \mathrm{MHz}$. $\left.\mathrm{CDCl}_{3}\right): \delta$ 160.74. 157.80, 147.27. 144.56, 144.18. 141.56. 131.47. 127.14. 121.99. 121.43, 114.54, 101.75, 77.26, 59.74, 56.42. 55.77. 42.56, 39.60. 27.57, 23.59. 16.96.

Preparation of compound 3. A solution of compound 2 (3.63 g. $5.0 \mathrm{nmmol})$. 2-mercaptoethanol $(3.63 \mathrm{~g}, 5.0 \mathrm{~nm}$ ol). 2,2'-azobisisobutyronitrile $(3.5 \mathrm{~mL}, 50 \mathrm{nmol})$ in $\mathrm{CHCl}_{3}(25$ $\mathrm{mL}$ ) was prepared and consequently refluxed for $12 \mathrm{~h}$. Then the reaction liquid was washed with brine $(20 \mathrm{~mL} \times 2)$, dried $\left(\mathrm{MgSO}_{4}\right)$ and evaporated under reduced pressure to give the crude product which was purified by colunn cluromatography on silica with $\mathrm{CHCl}_{3}: \mathrm{CH}_{3} \mathrm{OH}:\left(\mathrm{C}_{2} \mathrm{H}_{5}\right)_{3} \mathrm{~N} \quad 5: 1: 1$ to afford the pure sulfide $32.9 \mathrm{~g}$ ( $66 \%$ yield). ${ }^{1} \mathrm{H}$ NMR (400 $\left.\mathrm{MHz} . \mathrm{CDCl}_{3}\right), \delta: 8.67$ (d. $\left.J=4.8 \mathrm{~Hz}, 2 \mathrm{H}, \mathrm{ArH}\right) .7 .99$ (d, $J=$ $9.2 \mathrm{~Hz}, 2 \mathrm{H}, \mathrm{ArH}), 7.49$ (s, 2H, ArH). $7.37-7.38(\mathrm{~m}, 4 \mathrm{H}$. ArH). 7.00 (s. 2H, ArH) 6.77 (br. $2 \mathrm{H}, \mathrm{PhC}^{*} \mathrm{H}$ ), 3.89 (s. $6 \mathrm{H}$. $\left.\mathrm{OCH}_{3}\right) .3 .68(\mathrm{~s}, 4 \mathrm{H}) .3 .36$ (br. $\left.2 \mathrm{H}\right), 2.69-2.46(\mathrm{~m}, 10 \mathrm{H}), 2.45$ (br. 2H) 2.30 (br, 2H) $1.75-1.43$ (m, 22H): HRMS (ESI). $m z: 881.4077\left(\mathrm{M}+\mathrm{H}^{-}\right)$.

Preparation of ligand 1 . A $50 \mathrm{~mL}$ flask was charged with compound 3 (1.02 g. $1.14 \mathrm{mmol}$ ). $50 \mathrm{mg} \cdot \mathrm{mL}^{-1} \mathrm{OsO}_{4}(0.56$ $\mathrm{mL}$. $0.1 \mathrm{l}$ numol). NMO (0.86 g. $7.6 \mathrm{mmol})$ and $\mathrm{THF} /$ $t$-BuOH $(3: 1) 30 \mathrm{~mL}$. The mixture was stirred at room temperature until TLC indicated that compound 2 disappeared. $\mathrm{Na}_{2} \mathrm{SO}_{3}(5.00 \mathrm{~g})$ was then added and stirred for $\mathrm{I}$ h. The mixture was filtered, dried over anhydrous $\mathrm{MgSO}_{4}$ and evaporated to give crude product which was further purified by colunn chromatography on silica $\left(\mathrm{CHCl}_{3}\right.$ : $\left.\mathrm{CH}_{3} \mathrm{OH}:\left(\mathrm{C}_{3} \mathrm{H}_{3}\right)_{3} \mathrm{~N} 5: \mathrm{l}: \mathrm{l}\right)$ to afford the pure ligand $10.85 \mathrm{~g}$ (79\% yield). ${ }^{1} \mathrm{H}$ NMR $\left(400 \mathrm{MHz} . \mathrm{CDCl}_{\hat{j}}\right), \delta$ : $8.66(\mathrm{~d}, J=4.8$ Hz, 2H. Ar-H). 8.00 (d. $J=9.2 \mathrm{~Hz}, 2 \mathrm{H}, \mathrm{ArH}$ ), 7.49 (t. $2 \mathrm{H}$. ArH). 7.37-7.38 (m, 4H. ArH), 6.99 (s. 2H. ArH), 6.75 (br. 2H. $\mathrm{PhC}^{*} \mathrm{H}$ ). 4.06 (br. $4 \mathrm{H}$ ), 3.89 (s. $6 \mathrm{H}_{\mathrm{OCCH}}$ ), 3.39 (br. $2 \mathrm{H}), 3.14-2.99(\mathrm{~m}, 10 \mathrm{H}), 2.54$ (br, $2 \mathrm{H}) .2 .33$ (br. $2 \mathrm{H}$ ), 1.86-
1.21 (m. 22H): ${ }^{13} \mathrm{C}$ NMR (I00 MHz, CD $\left.30 D\right): \delta 171.49$. 167.69, 163.92. 152.75. 148.57, 147.48, 144.58. 143.63. $138.82,130.52,129.23,128.45,126.24 .109 .84,77.33$. 74.62. 56.36, 55.80. 55.10. 52.95, 34.49, 26.16. 25.48, 14.09: HRMS (ESI), $m: 2: 945.3897\left(\mathrm{M}+\mathrm{H}^{+}\right)$.

Typical recycling procedure for the asymmetric aminohydroxylation with iso-Propyl trans-cinnamate as substrate. A solution of benzyloxycarbonyl carbamate (469 $\mathrm{mg}$. $3.1 \mathrm{mmol}$ ) in $n-\mathrm{PrOH}(4 \mathrm{~mL})$ was sequentially treated with $\mathrm{NaOH}$ (122 mg. $3.05 \mathrm{mmol}$ in $7.5 \mathrm{~mL}$ water) and freshly prepared $t-\mathrm{BuOCl}(0.35 \mathrm{~mL}, 3.05 \mathrm{mmol})$. After stirring for 5 min at room temperature, a solution of ligand $1(80 \mathrm{mg}, 0.1$ nunol in $3.5 \mathrm{~mL}$ of $n-\mathrm{PrOH}$ ) and iso-Propyl thons-cimanate (190 $\mathrm{mg} .1 .0 \mathrm{mmol}$ ) was added followed by $\mathrm{K}_{2} \mathrm{OsO}_{2}(\mathrm{OH})_{4}$ (14.7 $\mathrm{mg} .0 .04 \mathrm{mmol}$ ) and $\mathrm{PEG}-400(1.5 \mathrm{~mL})$. The reaction mixture was stirred until starting material disappeared by TLC analysis. $n-\mathrm{PrOH}$ was then removed under reduced pressure and the water layer was extracted with $\mathrm{Et}_{2} \mathrm{O}(20 \mathrm{~mL} \times 2)$. Ether layer was dried over anliydrous $\mathrm{MgSO}_{4}$ and evaporated to give the crude product. which was purified by silica gel chromatography (hexen/EtOAc, 4:1) to provide protected $\beta$ aminoalcohol. Then benzyloxycarbonyl carbamate (469 $\mathrm{mg}$. 3.1 mumol) in $n-\mathrm{PrOH}(7 \mathrm{~mL})$, the proper amount of $\mathrm{NaOH}$ (approximately $60 \mathrm{mg}, \mathrm{pH}=11)$, t-butylhypocllorite $(0.35$ $\mathrm{mL} .3 .05 \mathrm{mmol}$ ) and $\mathrm{K}_{2} \mathrm{OsO}(\mathrm{OH})_{4}(7 \mathrm{mg} .0 .02 \mathrm{mmol})$ were added to regenerate the reaction conditions. iso-Propyl tromscinuamate ( $190 \mathrm{mg} .1 .0 \mathrm{~mm}$ ol) was then added. Similar workup and purification was repeated for 5 times.

Acknowledgments. We thank the National Natural Science Foundation of China (NSFC) for funancial support (Nos.: 20272082. 20572131).

\section{References}

1. Li. G.: Chang. H. T; Sharpless, K. B. Angew. Chem Int Ed. Engl. 1996. 35,451

2. Rudolph. J; Sennhenn, P. C.: Vlaar. C. P.: Sharpless. K. B. Angew: Chen. Int. Ed. Engl. 1996. 35. 2810

3. Goossen. L. J.: Liu. H.: Dress. K. R.: Sharpless. K. B. Angew Chent Int Ed Engl 1999. 38. 1080

4. Demko. Z. P: Bartsch, M.: Sharpless. K. B. Org. Lett. 2000. 2. 2221 .

5. Ager. D. J.: Prakash. I.: Schaad. D. R. Chem. Rev. 1996. $96,835$.

6. Lee. J.-C.: Kim. G. T.: Shim. Y. K.: Kang. S. H. Tetrahedron Lett. 2001. +2. 4519 .

7. Kiml. I. H.: Kirk. K. L. Tetrahedron Lett. 2001. 12.8401

8. Nanadanan, E.; Phukan, P: Pais. G. C. G.: Sudalai, A. hid. $d$ Chem. $1999,38 B, 287$.

9. Song, C. E; Oh. C. R.: Lee, S. W: Lee. S.-G: Canali. L. Sherrington. D. C. Chent Commm. 1998. 22.2435.

10. Mandoli. A.: Pini. D.: Agostini. A.: Salvadori. P. Tetrohedron: Astnmetry 2000. H. 4039 .

11. Jo. H.: Han, S.-H.; Yang J. W.: Roh, E. J: Shin. U.-S: Song. C. E. Chem. Commun. 2003, 11.1312.

12. Yang. X. W: Liu, H. Q: Xu, M. H. Lin, G. Q. Terahedron: Astntmetry 2004. 15. 1915.

13. Jiang. R.: Kuang. Y. Q.: Sur1. X. L.: Zhang. S. Y. Tetrohedhon: Astmintetry 2004. 15.743

14. Kuang. Y. Q; Zhang. S. Y: Jiang, R. Tetrahedron Lett. 2002, 43. 3669.

15. Snider. B. B.: Zeng. H. B. J. Ong. Chem. 2003. 68.545 . 